\title{
Spatial modeling of cutaneous leishmaniasis in the Andean region of Colombia
}

\author{
Mauricio Pérez-Flórez ${ }^{1,2}{ }^{+}$, Clara Beatriz Ocampo', Carlos Valderrama-Ardila ${ }^{3}$, Neal Alexander ${ }^{1}$ \\ ${ }^{1}$ Centro Internacional de Entrenamiento e Investigaciones Médicas, Cali, Colombia \\ ${ }^{2}$ Pontificia Universidad Javeriana, Cali, Colombia ${ }^{3}$ Universidad Icesi, Departamento de Ciencias Biológicas, Cali, Colombia
}

\begin{abstract}
The objective of this research was to identify environmental risk factors for cutaneous leishmaniasis (CL) in Colombia and map high-risk municipalities. The study area was the Colombian Andean region, comprising 715 rural and urban municipalities. We used 10 years of CL surveillance: 2000-2009. We used spatial-temporal analysis - conditional autoregressive Poisson random effects modelling - in a Bayesian framework to model the dependence of municipality-level incidence on land use, climate, elevation and population density. Bivariable spatial analysis identified rainforests, forests and secondary vegetation, temperature, and annual precipitation as positively associated with CL incidence. By contrast, livestock agroecosystems and temperature seasonality were negatively associated. Multivariable analysis identified land use - rainforests and agro-livestock - and climate - temperature, rainfall and temperature seasonality - as best predictors of CL. We conclude that climate and land use can be used to identify areas at high risk of $C L$ and that this approach is potentially applicable elsewhere in Latin America.
\end{abstract}

Key words: cutaneous leishmaniasis - environmental risk factors - Colombian Andean region - spatial analysis

The World Health Organization (WHO) has classified leishmaniasis as a serious global public health problem, and as a neglected and re-emergent disease (WHO 2007). It comprises a group of diseases - cutaneous (CL), muco-cutaneous (ML) and visceral (VL) - caused by Leishmania parasites which, in the Americas, are transmitted by female Lutzomyia sandflies (Chaves \& Pascual 2006). Like all vector-borne infectious diseases (VBD), leishmaniasis is highly sensitive to environmental factors (Weber 2010). Climate affects the biology and ecology of the triad parasite-vector-reservoir, and hence the disease's spatial and temporal distribution (Ready 2010).

Vector distributions have been found to track environmental changes (Gebre-Michael et al. 2004, Michalsky et al. 2009), and WHO is promoting integration of new technological VBD monitoring tools, such as remote sensing and geographic information systems (GIS) (Bavia et al. 2005). Factors such as temperature, precipitation, vegetation cover, land use and natural phenomena such as El Niño or La Niña, have been associated with the occurrence of CL or VL, in patterns which depend on the region, ecological context and vector species (King et al. 2004, Bhunia et al. 2010, Valderrama-Ardila et al. 2010).

The global incidence of CL is estimated at 1.5 million new cases each year (OMS 2010). In the Americas the reported CL cases/year was 66,941 between 2003-2008 (Alvar et al. 2012). In Colombia the annual number of

doi: 10.1590/0074-02760160074

+Corresponding author: mauricioperez@javerianacali.edu.co

Received 26 February 2016

Accepted 27 May 2016 reported cases has increased from an average of approximately 6,500 in the $1990 \mathrm{~s} ; 14,000$ in the 2000 s; to 17,420 between 2005-2009, CL comprising more than $95 \%$ of these (INS 2010, Alvar et al. 2012). Major epidemics in Colombia have occurred in the Andean region (Pardo et al. 1999, 2006, Cárdenas et al. 2005, 2006, Flórez et al. 2006, Santamaria et al. 2006, Rodríguez-Barraquer et al. 2008), with Lutzomyia species from the verrucarum group being the dominant vectors (Bejarano et al. 2003).

The current study seeks to identify environmental factors associated with the incidence of CL in the Colombian Andes and hence map the risk at the level of municipality. This map is expected to serve as a support tool for surveillance of leishmaniasis in Colombia and contribute to reducing the impact of this disease.

\section{MATERIALS AND METHODS}

Population and study area - The study area was the Colombian Andean region which comprises 24.5\% of the country's land surface area, or $278,600 \mathrm{~km}^{2}$ (Etter \& van Wyngaarden 2000) and includes the western, central and eastern mountain ranges (cordilleras), and much of the Magdalena and Cauca river valleys (Fig. 1). More specifically, we followed the definition used by the Instituto Alexander von Humboldt (IAvH) by taking those parts of the country above $400 \mathrm{~m}$ (Rodríguez et al. 2006). This region is characterised by a mosaic of savanna ecological regions, tropical forests and wooded areas with diverse topography, climate and vegetation (King et al. 2004, Sandoval et al. 2006, Cárdenas et al. 2008). It also includes large areas devoted to agriculture as well as the country's most populous cities.

The unit of analysis was the municipality because this is the finest level captured consistently by epidemiological surveillance in Colombia. Of 860 rural and urban municipalities overlapping the Andean region, i.e. lying at least partly above $400 \mathrm{~m}$, the study included 


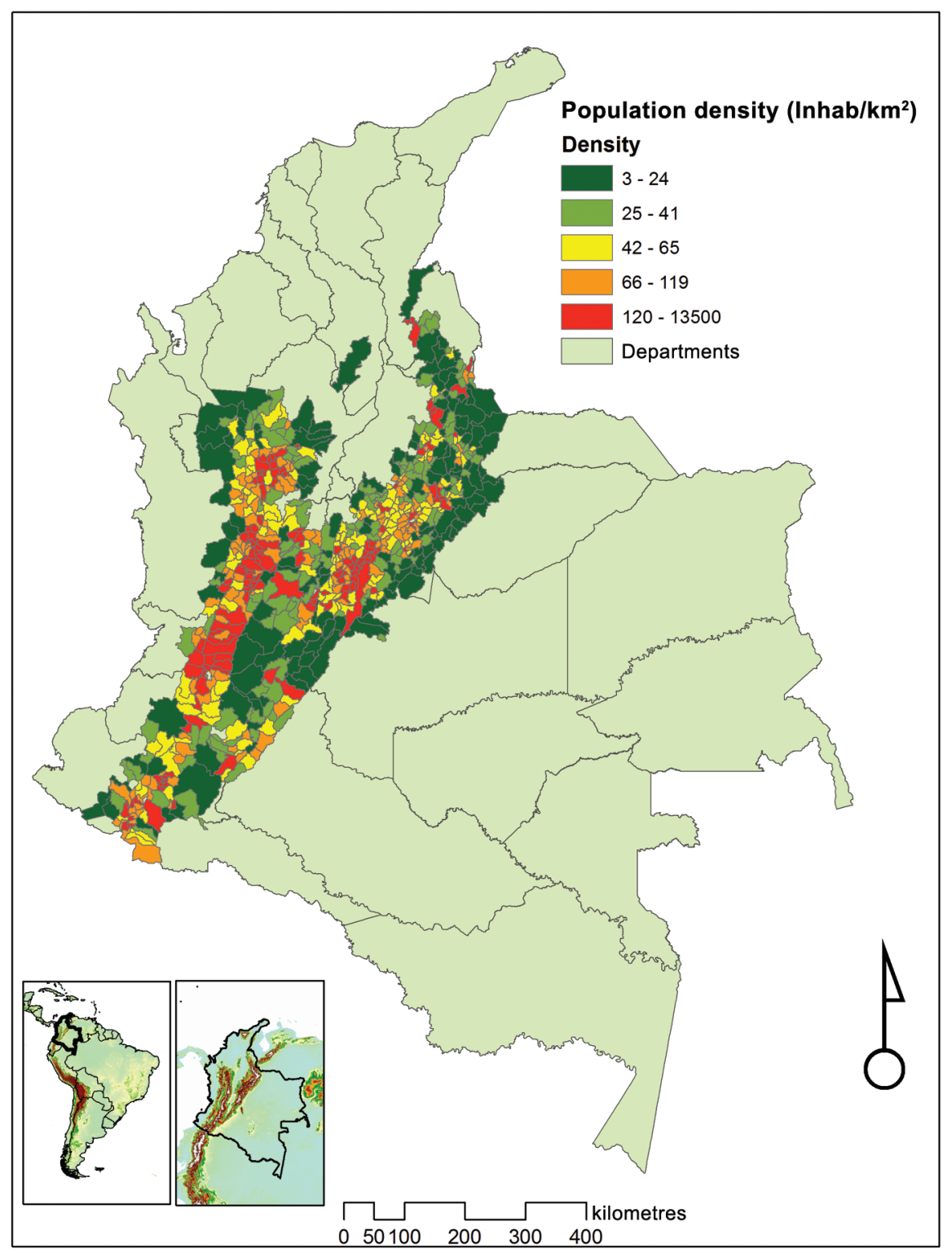

Fig.1: map of the area of study (Andean region) showing population density (number of inhabitants per square kilometre).

those 715 having more than $90 \%$ of their area within this region, i.e. altitude above $400 \mathrm{~m}$. These 715 municipalities belong mainly $(\mathrm{n}=696)$ to 13 Andean departments (states) (Boyacá, Cundinamarca, Antioquia, Santander, Nariño, Tolima, Valle del Cauca, Cauca, Huila, Norte de Santander, Caldas, Risaralda and Quindío), with the remaining 19 from six other departments (Casanare, Meta, Putumayo, Chocó, Bolivar and Cesar). According to the DANE (2005) national census, the population of these 715 municipalities was $27,416,481$ (66.1\% of national total), averaging approximately 38,000 each.

Variables and sources - CL incidence - The outcome of interest is the annual incidence rate of CL for the period 2000-2009. The numerator (annual number of CL cases by municipality) comes from the mandatory reporting system SIVIGILA, supplied by the Ministry of Health and Social Protection (Ministerio de Salud y Protección Social or MSPS) and are new and recurrent reported cases of CL. Data were considered good quality, and retained in the analysis, if they had information on municipality of origin and type of disease (CL, ML or VL). The denominator (number of people) at the middle of the study period was taken from the DANE (2005) national census or population projections. The latter were used when DANE reported partial information on the number of inhabitants due to access problems at the time of the census.

We use all available environmental variables. We consider 31 variables as potential environmental risk factors: 19 climatic, one topographic, one demographic and 10 on land use. 
Land use - Land use was obtained from the Colombian Andes ecosystems map of IAvH which was made at a scale of 1:250,000 (IAvH 2005, Rodríguez et al. 2006) from interpretation of satellite images and thematic information for the year 2005. This map is in digital raster format (.img) of $32 \times 32$ metres but was manipulated in vector format. The 1:250,000 scale refers to the level of detail at which satellite images were interpreted. This map identifies 142 different ecosystems of the Colombian Andean region (112 natural and 30 modified) (Rodríguez et al. 2006), grouped in 10 categories of coverage for the current study: rainforests; dry forests; forest and secondary vegetation; shrub and xeric vegetation; páramo (alpine ecosystem above the tree line) and snow; coffee agroecosystems; mechanised crops (rice and sugarcane); livestock agroecosystems; unmechanised crops, such as fruit, vegetables and intercropping; others (urban areas, marshes, ponds, lakes, lagoons, rivers, beaches, wasteland, etc.).

Climate - Bioclimatic variables (Supplementary data) come from remote sensing systems available in the WorldClim database (http://www.worldclim.org). We used 19 climate surfaces (raster format at spatial resolution of $1 \mathrm{~km}$ ) derived from monthly values of temperature $\left({ }^{\circ} \mathrm{C}\right)$ and precipitation (mm), e.g. annual average, precipitation or mean temperature in the coldest quarter, and similarly for the warmest, wettest and driest quarters (Hijmans et al. 2005).

Elevation - A raster image of a NASA digital elevation model was acquired in EROS Data Center (edc.usgs. gov), from the mission "Shuttle Radar Topography Mission - SRTM", at a resolution of 3 arc-seconds $(\sim 90 \mathrm{~m})$.

Population density - Population density (Fig. 1), i.e. the number of inhabitants per square kilometre, was obtained for each municipality, based on the DANE (2005) national census and a digital of map of the municipalities from IGAC (1:100.000).

Information processing - ArcMap 9.3 software with Spatial Analyst was used for analysis of shapefile and raster data, and for extracting numeric data from satellite images. It was used to overlap the map of municipalities with the ecosystem (ground coverage) map and the 19 bioclimatic and elevation layers. Then summary statistics were obtained for each municipality, such as percentage coverage with each ecosystem, and averages of climatic variables and elevation.

Statistical analysis - Correlation analysis - Collinearity between the variables, in terms of Spearman's correlation coefficient $(r)$, was used to guide data reduction.

Spatial analysis - We used a random-effects Poisson model, allowing spatial correlation via an intrinsic conditional autoregressive (CAR) prior. The response variable $\left(Y_{i t}\right)$ was the total number of CL cases in municipality $i$ by year in 2000-2009 $(t=1, \ldots, 10)$, and independent variables $\left(x_{i}\right)$ were the selected land use and climatic factors, population density and year (Supplementary data). The model included a logarithmic link function and logarithm of population size as an offset, so that exponentiating the regression coefficients $a_{i}$ estimates incidence rate ratios (IRRs), not standardised for age. These are reported with their respective Bayesian 95\% credible intervals
(95\% $\left.\mathrm{CI}_{\text {cred }}\right)$. We chose this CAR model as it takes into account the lack of independence in the data - i.e. spatial autocorrelation - and uses it to improve estimates based on neighbor information (Gelfand \& Vounatsou 2003, Heinen \& Rengifo 2003, Ready 2008). We also included unstructured random effects (Thomas et al. 2004). For the annual average temperature, a quadratic relationship was considered because of the vector's aversion to extreme hot or cold and predominance at intermediate altitudes (Pardo et al. 1999, Young \& Duncan 1994).

Spatial analysis was conducted in a Bayesian framework using non-informative large-variance priors. The intercept $\left(a_{0}\right)$ was assigned an improper uniform prior distribution (Thomas et al. 2004). The other $a$ 's were assigned normal priors distributions with mean zero and variance $10^{5}$. For the structured components $\left(b_{i}\right)$, a Gaussian CAR prior distribution was assumed, with contiguity as criterion of proximity between municipalities and a scalar argument $t_{b}$ representing the precision parameter (inverse variance). For $h_{i}$, normally distributed priors with zero mean and variance $1 / t_{h}$ were assumed. For both $t_{b}$ and $t_{h}$, Gamma priors with parameters 0.5 and 0.0005 (mean $10^{3}$ and variance $2 \times 10^{6}$ ) were assumed. In sensitivity analysis, Gamma priors with parameters 0.1 and 0.1 (mean 1 and variance 100) were used for $t_{b}$ and $t_{h}$.

Spatial analysis used the GeoBUGS v1.4.3 component of the WinBUGS v1.2 software. The map of municipalities was converted from shapefile to SPlus format using a program written by Ms Yue Cui, University of Minnesota (Cui 2006).

Models were fitted using Markov Chain Monte Carlo. In order to speed convergence in the estimation of the parameters and reduce autocorrelation, each independent variable was centered by subtracting its average (Thomas et al. 2004). Two chains were run with different starting values. Convergence was evaluated by monitoring parameters $a_{0}, a_{k}, a_{i}, t_{b}$ and $t_{h}$. After 50,000 'burnin' iterations, visual inspection of the trace plots showed stabilisation and overlap of the two chains, and on this basis we concluded that convergence had occurred. 50,000 additional iterations were run for estimation of parameters' posterior distributions.

Spatial analysis consisted of two phases: bivariable, then multivariable analysis using stepwise-forward selection. The model started with the independent variable most associated with the outcome (on basis of size of $a_{i}$ ). New variables (biologically important and statistically significant) were added until no more were statistically significant.

Risk map - The results of the multivariate model were used to estimate the expected number of cases for each year. For the last year of the study period, 2009, these expected numbers were used to estimate the corresponding rates for each municipality, which were mapped using ArcMap 9.3. This software was also used to generate choropleth maps of observed incidence rate of CL by municipality. Approval was obtained from the Institutional Ethics Committee on Human Research (CIEIH) of CIDEIM and the Institutional Ethics Committee for Human Research of Universidad del Valle. The Ministry of Health and Social Protection (MSPS) also approved the use of its epidemiological data. 

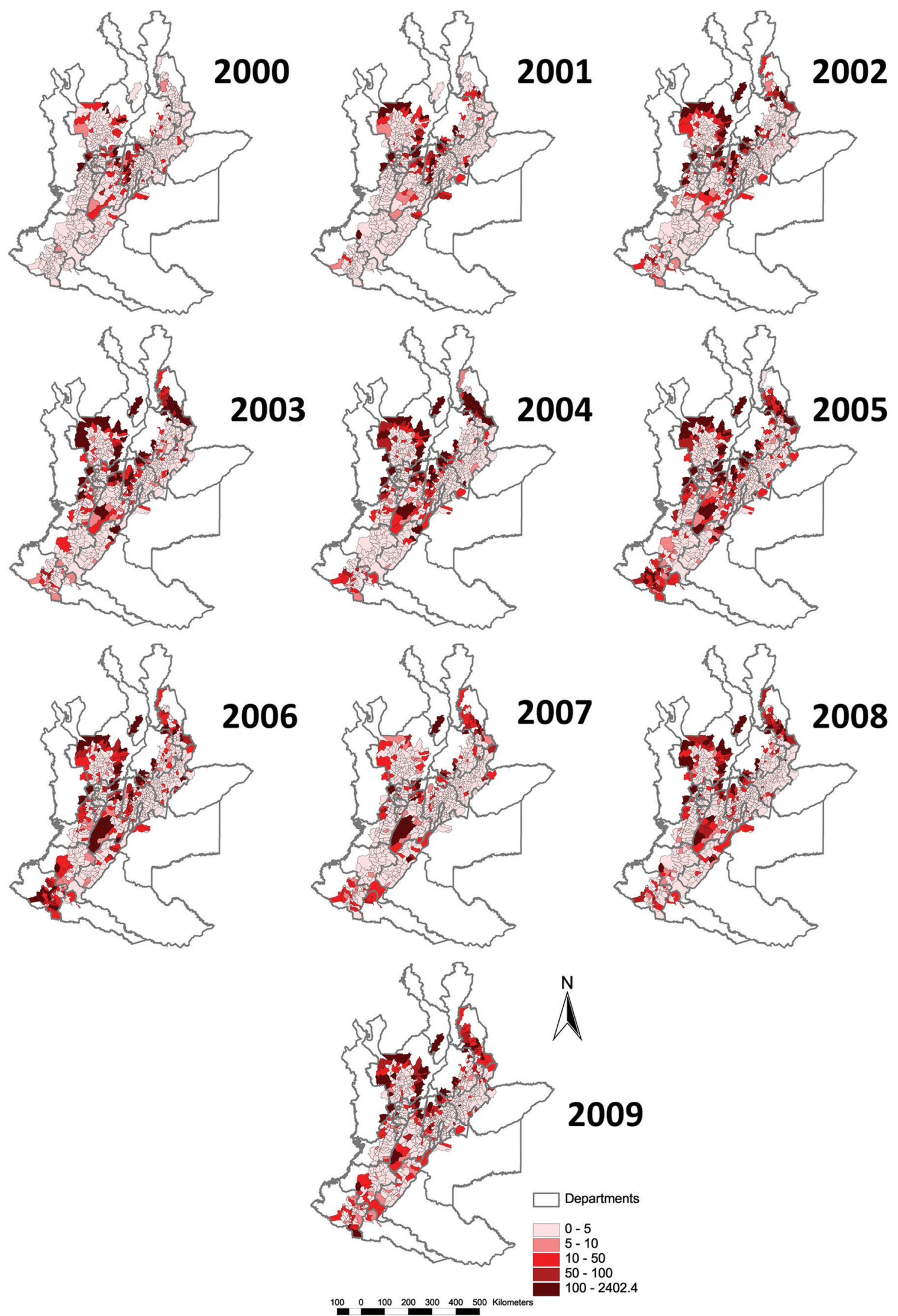

Fig. 2: observed incidence rate of cutaneous leishmaniasis in the Andean region of Colombia by year from 2000-2009 (per 100,000 inhabitants) (Source: Ministry of Health and Social Protection). 


\section{RESULTS}

Incidence - A total of 90,413 cases of leishmaniasis (CL, ML, VL and unspecified) were reported in Colombia in the period 2000-2009, of which $85.4 \%(77,210 / 90,413)$ had the municipality recorded and only $2 \%$ were unspecified cases. Of these, $78.7 \%(60,794 / 77,210)$ are from the 860 municipalities that fully or partially overlap with the Andean region (above $400 \mathrm{~m})$, with $38.8 \%(29,949 / 77,210)$ from the 715 municipalities in the main analysis on the basis of having more than $90 \%$ of their surface area in the region. We use 29,542 cases of CL in the Andean region giving an overall incidence rate of 107.8 cases $(29,542 / 27,416,481)$ per 100,000 inhabitants for the tenyear period, or 10.8/100,000/year. We performed a temporal analysis of incidence rates per year (Fig. 2).

Bivariable analysis - Six temperature variables were strongly correlated $(r>0.7)$ with mean annual temperature and six precipitation variables with annual precipitation: these 12 were excluded from spatial analysis (Supplementary data). There was also a strong negative correlation between the mean annual temperature and elevation $(\mathrm{r}=$ -0.991), so the latter was also excluded, on the basis of temperature having a more direct effect on the vector.

In addition, páramo coverage was excluded due to its lack of contribution to transmission in Colombia, as was the 'other' category for being too heterogeneous, and (i) dry forest, (ii) shrubland and xeric vegetation, and (iii) technified crops for their rarity $(0.03 \%, 0.6 \%$ and $1.7 \%$ respectively). Finally, several climatic variables were excluded on the basis of homogeneity over the study area, specifically average annual temperature diurnal range, isothermality (mean diurnal temperature range as a percentage of annual range) and annual temperature range, with coefficients of variation $7.7 \%, 5.5 \%$ and $9.0 \%$, respectively. Ten variables showing low collinearity (all 45 distinct off-diagonal pairwise correlations $<0.7$ ) were retained for spatial analysis (Table I).

The first phase of spatial analysis used 10 independent variables and six were associated with CL incidence.
The incidence showed an inverted U-shaped (quadratic) relationship with average annual temperature, however this significance disappeared in multivariable analysis.

CL incidence was positively associated with rainforest cover, with a $2.8 \%$ increase $\left(95 \% \mathrm{CI}_{\mathrm{Cred}}: 2.0-3.7 \%\right)$ per additional percent of coverage. It also increased by $2.1 \%\left(95 \% \mathrm{CI}_{\text {Cred }}: 0.6-3.6 \%\right)$ for each additional percent coverage with forest and secondary vegetation.

CL incidence was positively associated with annual rainfall, increasing $0.16 \%\left(95 \% \mathrm{CI}_{\mathrm{Cred}}: 0.12-0.20 \%\right)$ per millimetre. By contrast, livestock agroecosystems and temperature seasonality (i.e. standard deviation of monthly temperature averages) showed a negative association with CL incidence, decreasing 3.0\% $\left(95 \% \mathrm{CI}_{\mathrm{Cred}}\right.$ : $1.9-4.1 \%)$ per percent coverage with livestock agroecosystems and $3.0 \%\left(95 \% \mathrm{CI}_{\mathrm{Cred}}: 0.1-5.9 \%\right)$ per ${ }^{\circ} \mathrm{C}$ of seasonal variation in temperature.

Multivariable analysis - In model 1 rainforest coverage was added to temperature and both retained statistically significance (Table II). Then annual precipitation and livestock agroecosystems coverage were added in turn (models 2 and 3). After we added temperature seasonality and all five variables were statistically significant (model 4). Finally, when the forest and secondary vegetation coverage was added, it lacked statistical significance, so model 4 was considered final.

The temporal component of the analysis (Fig. 3) had as reference level the year $2004(\mathrm{IRR}=1)$. CL incidence increased from 2000-2003, dropped sharply in 2004 before rebounding to another peak in 2005, then dropping back again.

Risk map - Municipality-level risks were mapped from the expected annual incidence rates from model 4 (Fig. 4). It is noted that municipalities at highest risk (expected annual rate $>100$ cases per 100,000 inhabitants) belong mainly to departments of Santander and Norte de Santander, Antioquia, Cundinamarca and Tolima.

TABLE I

Bivariable spatial analysis of factors associated with cutaneous leishmaniasis incidence in the Andean region of Colombia for 2000-2009

\begin{tabular}{|c|c|c|c|}
\hline Independent variable & IRR & Change $(\%)$ & $95 \% \mathrm{CI}_{\text {Cred }}^{\mathrm{a}}$ \\
\hline Rainforests (\%) & $1.028 *$ & $2.8 \%$ & $(2.0 \% ; 3.7 \%)$ \\
\hline Forest and secondary vegetation (\%) & $1.021^{*}$ & $2.1 \%$ & $(0.6 \% ; 3.6 \%)$ \\
\hline Coffee agroecosystems in association (\%) & 1.003 & $0.3 \%$ & $(-1.8 \% ; 2.5 \%)$ \\
\hline Livestock agroecosystems (\%) & $0.970 *$ & $-3.0 \%$ & $(-4.1 \% ;-1.9 \%)$ \\
\hline Non-technified crops (\%) & 1.002 & $0.2 \%$ & $(-0.7 \% ; 1.2 \%)$ \\
\hline \multicolumn{4}{|l|}{ Biol: Annual mean temperature $\left({ }^{\circ} \mathrm{C}\right)$} \\
\hline - Linear & $1.155^{*}$ & $15.5 \%$ & $(10.2 \% ; 21.2 \%)$ \\
\hline - Quadratic & $0.985^{*}$ & $-1.5 \%$ & $(-2.2 \% ;-0.7 \%)$ \\
\hline Bio4: Temperature seasonality $\left({ }^{\circ} \mathrm{C}\right)$ & $0.970^{*}$ & $-3.0 \%$ & $(-5.9 \% ;-0.1 \%)$ \\
\hline Bio12: Annual precipitation (mm) & $1.0016^{*}$ & $0.16 \%$ & $(0.1 \% ; 0.2 \%)$ \\
\hline Bio15: Precipitation seasonality (\%) & 0.995 & $-0.5 \%$ & $(-3.9 \% ; 3.2 \%)$ \\
\hline Population density (per inhabitant per $\mathrm{km}^{2}$ ) & 1.001 & $0.1 \%$ & $(-0.4 \% ; 0.6 \%)$ \\
\hline
\end{tabular}

a: $95 \% \mathrm{CI}_{\mathrm{Cred}}$ : 95\% Bayesian credible interval; *: statistically significant (CI excludes 1); IRR: incidence rate ratio. 
TABLE II

Multivariable spatial analysis of factors associated with cutaneous leishmaniasis incidence in the Andean region of Colombia for 2000-2009

\begin{tabular}{|c|c|c|}
\hline Model & IRR & $95 \% \mathrm{CI}_{\mathrm{Cred}}{ }^{\mathrm{a}}$ \\
\hline \multicolumn{3}{|l|}{ Model 1: Temperature + Rainforest coverage } \\
\hline Biol: Annual mean temperature $\left({ }^{\circ} \mathrm{C}\right)$ - Linear & $1.196^{*}$ & $(1.1350 ; 1.2633)$ \\
\hline Quadratic & $0.991^{*}$ & $(0.9827 ; 0.9983)$ \\
\hline Rainforest (\%) & $1.034^{*}$ & $(1.0242 ; 1.0438)$ \\
\hline \multicolumn{3}{|l|}{ Model 2: Temperature + Rainforests + Precipitation } \\
\hline Biol: Annual mean temperature $\left({ }^{\circ} \mathrm{C}\right)$ - Linear & $1.151^{*}$ & $(1.0924 ; 1.2115)$ \\
\hline Quadratic & 0.992 & $(0.9847 ; 1.0004)$ \\
\hline Rainforests (\%) & $1.023^{*}$ & $(1.0123 ; 1.0321)$ \\
\hline Bio12: Annual precipitation (mm) & $1.001^{*}$ & $(1.0004 ; 1.0013)$ \\
\hline \multicolumn{3}{|c|}{ Model 3: Temperature + Rainforests + Precipitation + Livestock agroecosystems } \\
\hline Biol: Annual mean temperature $\left({ }^{\circ} \mathrm{C}\right)$ - Linear & $1.147 *$ & $(1.0908 ; 1.2080)$ \\
\hline Rainforests (\%) & $1.019 *$ & $(1.0088 ; 1.0314)$ \\
\hline Bio12: Annual precipitation (mm) & $1.001 *$ & $(1.0005 ; 1.0013)$ \\
\hline Livestock agroecosystems (\%) & $0.988^{*}$ & $(0.9765 ; 0.9986)$ \\
\hline \multicolumn{3}{|c|}{ Model 4: Temperature + Rainforests + Precipitation + Livestock agroecosystems + Temperature seasonality } \\
\hline Biol: Annual mean temperature $\left({ }^{\circ} \mathrm{C}\right)$ - Linear & $1.176^{*}$ & $(1.1158 ; 1.2450)$ \\
\hline Rainforests $(\%)$ & $1.017 *$ & $(1.0061 ; 1.0289)$ \\
\hline Bio12: Annual precipitation (mm) & $1.001^{*}$ & $(1.0004 ; 1.0014)$ \\
\hline Livestock agroecosystems (\%) & $0.986^{*}$ & $(0.9753 ; 0.9977)$ \\
\hline Temperature seasonality $\left({ }^{\circ} \mathrm{C}\right)$ & 0.942 & $(0.9152 ; 0.9673)$ \\
\hline
\end{tabular}

a: 95\% $\mathrm{CI}_{\text {Cred }}: 95 \%$ Bayesian credible interval; *: statistically significant (CI excludes 1); IRR: incidence rate ratio.

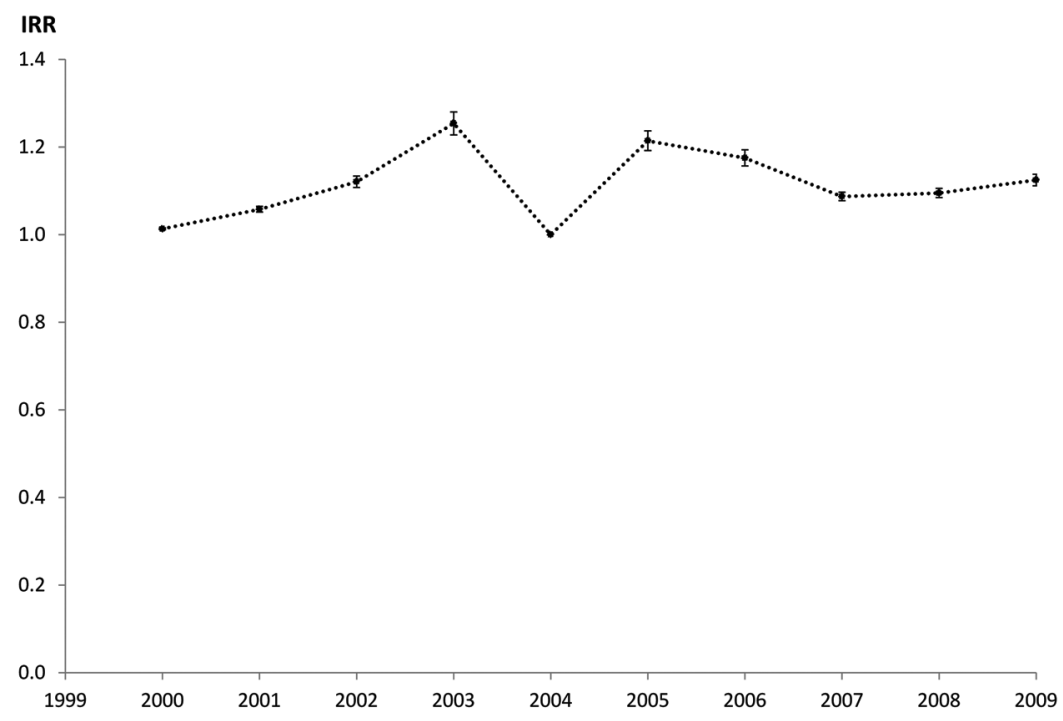

Fig. 3: incidence rate ratio over time, relative to 2004.

\section{DISCUSSION}

Leishmaniasis incidence in Colombia has increased over time and in spatial extent, suggesting a need for new surveillance tools (Pinzon et al. 2005). The current study used an "ecologic" design (analysis of aggregated data) to identify environmental factors associated with leishmaniasis incidence in the Colombian Andes.
Incidence rate - We restricted the study to the Andean region because the detailed IAvH ecosystem mapping was not available for other parts of Colombia. We found an overall incidence rate of 10.8/100,000/year in the Andean region. The deficit relative to the national rate (23.4) can be attributed to this study region containing the largest urban centres. The 715 municipalities ly- 


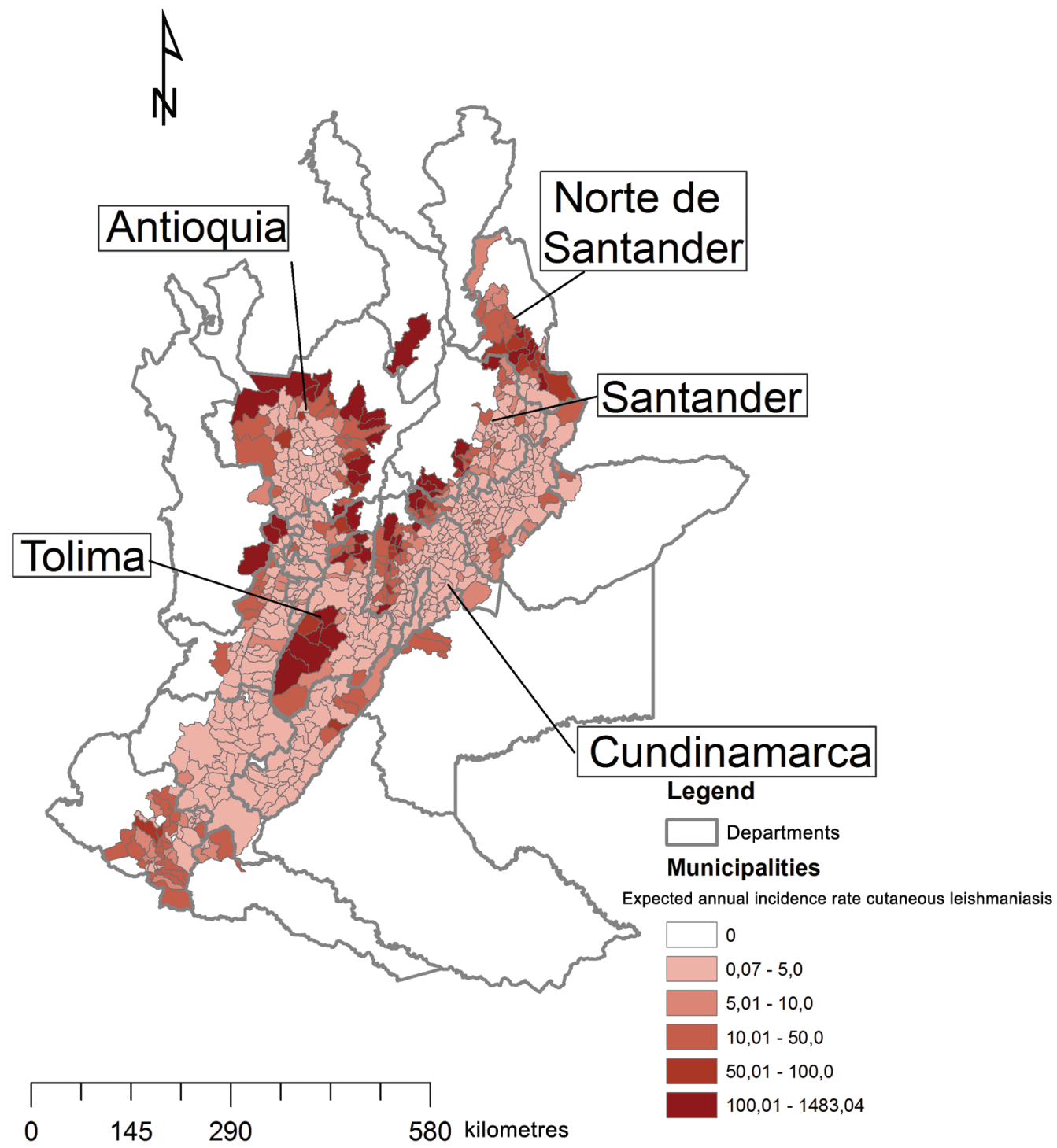

Fig. 4: risk map of expected incidence (per 100,000 inhabitants) in the Andean region of Colombia, by municipality, obtained from a predictive model based on environmental factors (rainforest coverage, coverage livestock agroecosystems, temperature, rainfall and temperature seasonality).

ing at least $90 \%$ within this region contributed $38.8 \%$ of those cases whose location was recorded. The 145 municipalities partly overlapping the Andean region, but with at least of $10 \%$ of their area outside - so not included in the current study - contributed 30,845 cases, compared to 29,949 from 715 municipalities in the main analysis. Correspondingly, a high incidence is visible in Fig. 4 round the edges of the study region. Hence a surprisingly high proportion of cases originated from the fringes of the Andean region.

Most studies exploring environmental risk factors for CL have reported numbers of cases with no population denominator. The few calculations of incidence in such studies include 28.5 per 100,000 per year in the state of Bahia, Brazil (Franke et al. 2002) and 670 in Sidi-Bouzid, Tunisia (Salah et al. 2007), both much higher than that described in the current paper.
Environmental factors associated with incidence of $C L$ - Multivariable spatial analysis found five variables associated with $\mathrm{CL}$ incidence. A positive association with rainforest cover was found, as by Valderrama-Ardila et al. (2010) in their smaller scale study in Chaparral (Tolima), although here it is more precisely estimated. We found a negative association between incidence and livestock agroecosystems. This does not seem to have been described previously although can be explained by transformation of natural landscape from forest into grasslands (Zeilhofer et al. 2008, Gil et al. 2010). Replacement of forests by anthropogenic vegetation like crops and pastures has led to destruction of the natural habitat of vectors and reservoirs, decreasing the risk of infection (WHO 2007, Zeilhofer et al. 2008, Gil et al. 2010).

We found a positive relationship between CL incidence and temperature. This is consistent with other stud- 
ies in which temperature was associated with distribution of vectors (Thomson et al. 1999, Gebre-Michael et al. 2004, González et al. 2010) or human CL cases (Elnaiem et al. 2003, Chaves \& Pascual 2006, Bhunia et al. 2010).

In this study annual rainfall was also positively associated with CL incidence which is consistent with most previous studies (Thomson et al. 1999, Elnaiem et al. 2003, Ready 2008, Bhunia et al. 2010). In some places, higher rainfall tends to increase vegetation density (Michalsky et al. 2009) and hence vector abundance (Ostfeld et al. 2005), at least at a coarse level (Githeko et al. 2000). Higher annual rainfall may be associated with habitats, such as forest coverage, which favor transmission (Kapos et al. 1997, Turton \& Freiburger 1997). The negative association between temperature seasonality and incidence may be driven by the high seasonality in the southern fringe of the eastern cordillera, where it descends towards the eastern plains, conditions unfavorable to many phlebotomine species (Supplementary figure).

To our knowledge, this is the first spatial and temporal analysis of environmental risk factors for the Colombian Andean region. The map of King et al. (2004) used data from a single year (1994), with dichotomous response variable (presence or absence of at least one case reported in a municipality), and classical (non-spatial) logistic regression. A comparative visual analysis of the Andean region in these two risk maps does not seem to show a good agreement.

On the other hand, this does highlight a limitation of our study, namely that it modeled spatial-temporal variation in CL rate but not in climate and land use. For example, it cannot predict changes in incidence associated with inter-annual changes due to the El Niño climate phenomenon, as have been identified in northeastern Colombia (Cárdenas et al. 2006) or other causes. The temperature and rainfall data are from the WorldClim database which was constructed from data mainly from 1950-2000 and then interpolated to pixels of $1 \mathrm{~km}^{2}$. For the Andean region, uncertainty in these WorldClim estimates ranged from 0.2 to $>0.4^{\circ} \mathrm{C}$ for temperature, and $>10 \mathrm{~mm}$ for precipitation (Hijmans et al. 2005). At a finer time scale, in the Andean zone of Colombia, periods of lower rainfall were inversely associated with abundance peaks of Lutzomyia longiflocosa and L. columbiana vectors from the verrrucarum group that are the dominant species in the Andean region (Cárdenas et al. 2006, Ferro et al. 2011).

"Ecologic" studies are more susceptible to bias than those based on individuals (Borja-Aburto 2000) and they often - as here - use secondary data with possible measurement errors. Their aggregate-level analysis also precludes control of confounding at finer levels (Borja-Aburto 2000, Rochlin et al. 2011). This study used several data sources. Epidemiological data supplied by the public health surveillance in Colombia can have several limitations. For example, missing municipality information allowed use of only $85 \%$ of the records. Under-reporting is recognised nationally (King et al. 2004) and internationally (Miranda et al. 2005, Ready 2008, INS 2010). Changes in notification protocol over a period of nine years, a misclassification of origin municipality and migration of populations, among others, may cause over - or under - estimation of the true incidence rate. Municipal-level data aggregation is quite coarse, but this is the finest level at which Colombian surveillance data are compiled. For each municipality we represented temperature, rainfall and elevation by a single value (average) ignoring intra-municipal variation in climate and topography, which may be important for CL (Valderrama-Ardila et al. 2010).

On the other hand, in terms of strengths, we were able to include land use at a fine spatial resolution $(1: 250,000)$ and incidence data from a long period (10 years). Integration of GIS data from remote sensing with spatial modeling and epidemiological data allowed identification of environmental risk factors and construction of the first municipality-level risk map for $\mathrm{CL}$ in the Colombian Andes.

In conclusion, in this spatially and temporally extensive study of climate and land use as potential risk factors, we found that the incidence of CL in the Andean region of Colombia is positively associated with mean temperature, rainforest coverage and precipitation, and negatively associated with livestock agroecosystems and temperature seasonality. The integration of epidemiological data, remote sensing images, GIS and statistical modeling can be used to identify areas at high risk of CL. This approach is potentially applicable elsewhere in Latin America to support vector borne disease surveillance systems.

\section{ACKNOWLEDGEMENTS}

To the Ministry of Health and Social Protection (MSPS), for providing leishmaniasis epidemiological data for the period 2000-2009 that made this study possible; Drs Luisa Consuelo Rubiano and Nancy Saravia, for facilitating this interchange; and Rana Moyeed, for advice on the spatial analysis. This study was conducted in partial fulfillment of the Masters of Science degree in Epidemiology from the School of Public Health of the Universidad del Valle.

\section{REFERENCES}

Alvar J, Vélez ID, Bern C, Herrero M, Desjeux P, Cano J, et al. Leishmaniasis worldwide and global estimates of its incidence. PLoS ONE. 2012; 7: e35671.

Bavia ME, Carneiro DD, Gurgel HC, Madureira Filho C, Barbosa MG. Remote sensing and geographic information systems and risk of American visceral leishmaniasis in Bahia, Brazil. Parassitologia. 2005; 47(1): 165-9.

Bejarano EE, Rojas W, Uribe S, Velez ID. Systematics of the Lutzomyia species of the Verrucarum Theodor group, 1965 (Diptera: Psychodiadae). Biomedica. 2003; 23: 87-102.

Bhunia GS, Kumar V, Kumar AJ, Das P, Kesari S. The use of remote sensing in the identification of the eco-environmental factors associated with the risk of human visceral leishmaniasis (kala-azar) on the Gangetic plain, in north-eastern India. Ann Trop Med Parasitol. 2010; 104(1): 35-53.

Borja-Aburto VH. Estudios ecológicos. Salud Publica Mex. 2000; 42(6): 533-8.

Cárdenas R, Pabón E, Anaya H, Sandoval C. Presencia de Lutzomyia longiflocosa (Diptera: Psychodidae) en el foco de leishmaniasis tegumentaria americana del municipio de Ábrego, Norte de Santander. Primer registro para el departamento. Rev Inst Facultad Salud Universidad de Pamplona. 2005; 3: 7-14.

Cárdenas R, Sandoval CM, Rodríguez-Morales AJ, Franco-Paredes C. Impact of climate variability in the occurrence of leishmaniasis in northeastern Colombia. Am J Trop Med Hyg. 2006; 75(2): 273-7. 
Cárdenas R, Sandoval CM, Rodríguez-Morales AJ, Vivas P. Zoonoses and climate variability. Ann N Y Acad Sci. 2008; 1149: 326-30.

Cui Y. How to get adjacency matrix from WINBUGS with ARCVIEW(.shp) files [Internet]. Division of Biostatistics. Minneapolis: University of Minnesota; 2006 [updated 2015 May 06; cited 2012 Jan 15]. Available from: http://www.biostat.umn.edu/ brad/ yuecui/index.html.

Chaves LF, Pascual M. Climate cycles and forecasts of cutaneous leishmaniasis, a nonstationary vector-borne disease. PLoS Med. 2006; 3(8): e295.

DANE - Departamento Nacional de Estadísticas [Internet]. Colombia. Proyecciones de población [updated 2016 May 29; cited 2015 Mar 8]. 2005. Available from: http://www.dane.gov.co.

Elnaiem DE, Schorscher J, Bendall A, Obsomer V, Osman ME, Mekkawi A, et al. Risk mapping of visceral leishmaniasis: the role of local variation in rainfall and altitude on the presence and incidence of kala-azar in eastern Sudan. Am J Trop Med Hyg. 2003; 68: 10-7.

Etter A, van Wyngaarden W. Patterns of landscape transformation in Colombia, with emphasis in the Andean region. AMBIO. 2000; 29(7): 432-9.

Ferro C, Marín D, Góngora R, Carrasquilla MC, Trujillo JE, Rueda NK, et al. Phlebotomine vector ecology in the domestic transmission of American cutaneous leishmaniasis in Chaparral Colombia. Am J Trop Med Hyg. 2011; 85(5): 847-56.

Flórez M, Martínez JP, Gutiérrez R, Luna KP, Serrano VH, Ferro C, et al. Lutzomyia longipalpis (Diptera: Psychodidae) at a suburban focus of visceral leishmaniasis in the Chicamocha Canyon, Santander, Colombia. Biomedica 2006; 26(Suppl. 1): 109-20.

Franke CR, Staubach C, Ziller M, Schlüter H. Trends in the temporal and spatial distribution of visceral and cutaneous leishmaniasis in the state of Bahia, Brazil, from 1985 to 1999. Trans R Soc Trop Med Hyg. 2002; 96: 236-241.

Gebre-Michael T, Malone JB, Balkew M, Ali A, Berhe N, et al. Mapping the potential distribution of Phlebotomus martini and P. orientalis (Diptera: Psychodidae), vectors of kala-azar in East Africa by use of geographic information systems. Acta Trop. 2004; 90: 73-86.

Gelfand AE, Vounatsou P. Proper multivariate conditional autoregressive models for spatial data analysis. Biostatistics. 2003; 4(1): 11-25.

Gil JF, Nasser JR, Cajal SP, Juarez M, Acosta N, Cimino RO, et al. Urban transmission of American cutaneous leishmaniasis in Argentina: spatial analysis study. Am J Trop Med Hyg. 2010; 82(3): 433-40.

Githeko AK, Lindsay SW, Confalonieri UE, Patz JA. Climate change and vector-borne diseases: a regional analysis. Bull World Health Organ [Internet]. 2000; 78(9): 1136-47.

González C, Wang O, Strutz SE, González-Salazar C, Sánchez-Cordero V, Sarkar S. Climate change and risk of leishmaniasis in North America: predictions from ecological niche models of vector and reservoir species. PLoS Negl Trop Dis. 2010; 4(1): e585.

Heinen A, Rengifo E. Multivariate modelling of time series count data: an autoregressive conditional poisson model. Center for Operations Research and Econometrics. Louvain-la-Neuve: Catholic University of Louvain; 2003.

Hijmans RJ, Cameron SE, Parra JL, Jones PG, Jarvis A. Very high resolution interpolated climate surfaces for global land areas. Int J Climatol. 2005; 25: 1965-78.

IAvH - Instituto de Investigaciones de Recursos Biológicos Alexander von Humboldt. Mapa de ecosistemas de los Andes colombianos del año 2005 [map], Escala: 1:250.000. Bogotá DC; 2005.

INS - Instituto Nacional de Salud [Internet]. Colombia. Protocolo de vigilancia en salud pública de leishmaniasis. PRO-R02.016 [updated 2016 May 29, cited 2015 Feb 5]. 2010. Available from: http://www.ins.gov.co/.

Kapos V, Wandelli E, Camargo JL, Ganade G. Edge-related changes in environment and plant responses due to forest fragmentation in central Amazonia. In: Laurance WF, Bierregaard Jr RO, editors. Tropical forest remnants: ecology, management and conservation of fragmented communities. Chicago: University of Chicago Press; 1997. p. 33-44.

King RJ, Campbell-Lendrum DH, Davies CR. Predicting geographic variation in cutaneous leishmaniasis, Colombia. Emerg Infect Dis. 2004; 10: 598-607.

Michalsky EM, França-Silva JC, Barata RA, Lara e Silva FO, Loureiro AMF, Fortes-Dias CL, et al. Phlebotominae distribution in Janaúba, an area of transmission for visceral leishmaniasis in Brazil. Mem Inst Oswaldo Cruz. 2009; 104(1): 56-61.

Miranda MC, Posso CX, Rojas CA. Manual de normas y procedimientos para la atención de la leishmaniasis en los municipios de Valle del Cauca. Cali: Secretaria Departamental de Salud, Gobernación del Valle del Cauca y Centro Internacional de Entrenamiento e Investigaciones Médicas; 2005.

OMS - Organización Mundial de la Salud. Control de las leishmaniasis. Informe de una reunión del Comité de Expertos de la OMS sobre el Control de las Leishmaniasis. Serie de informes técnicos $\mathrm{n}^{\circ}$ 949. Ginebra: OMS; 2010. $200 \mathrm{pp}$.

Ostfeld RS, Glass GE, Keesing F. Spatial epidemiology: an emerging (or re-emerging) discipline. Trends Ecol Evol. 2005; 20(6): 328-36.

Pardo R, Ferro C, Lozano G, Lozano C, Cabrera O, Davies C. Flebótomos (Diptera: Psychodidae) vectores de leishmaniasis cutánea y sus determinantes ecológicos en la zona cafetera del departamento del Huila. In: Memorias XXVI Congreso de la Sociedad Colombiana de Entomología. Bogotá: Editorial Guadalupe Ltda; 1999. p. 147-163.

Pardo RH, Cabrera OL, Becerra J, Fuya P, Ferro C. Lutzomyia longiflocosa as suspected vector of cutaneous leishmaniasis in a focus of cutaneous leishmaniasis on the sub-andean region of Tolima department, Colombia, and the knowledge on sandflies by the inhabitants. Biomedica. 2006; 26(Suppl. 1): 95-108.

Pinzon E, Wilson JM, Tucker CJ. Climate-based health monitoring systems for eco-climatic conditions associated with infectious diseases. Bull Soc Pathol Exot. 2005; 98(3): 239-43.

Ready PD. Leishmaniasis emergence and climate change. Rev Sci Tech. 2008; 27(2): 399-412.

Ready PD. Leishmaniasis emergence in Europe. Euro Surveill. 2010; 15(10): 19505.

Rochlin I, Turbow D, Gomez F, Ninivaggi DV, Campbell SR. Predictive mapping of human risk for West Nile virus (WNV) based on environmental and socioeconomic factors. PLoS ONE. 2011; 6(8): e23280.

Rodríguez N, Armenteras D, Morales M, Romero M. Ecosistemas de los Andes colombianos. 2nd ed. Bogotá: Instituto de Investigación de Recursos Biológicos Alexander von Humboldt; 2006. 154 p.

Rodríguez-Barraquer I, Gongora R, Prager M, Pacheco R, Montero LM, Navas A, et al. Etiologic agent of an epidemic of cutaneous leishmaniasis in Tolima, Colombia. Am J Trop Med Hyg. 2008; 78(2): 276-82.

Salah AB, Kamarianakis Y, Chlif S, Alaya NB, Prastacos P. Zoonotic cutaneous leishmaniasis in central Tunisia: spatio temporal dynamics. Int J Epidemiol. 2007; 36(5): 991-1000.

Sandoval CM, Gutiérrez R, Cárdenas R, Ferro C. Species of Lutzomyia (Psychodidae, Phlebotominae) in endemic cutaneous and visceral leishmaniasis foci of the department of Santander, in the eastern range of the Colombian Andes. Biomedica. 2006; 26 (Suppl. 1): 218-27. 
Santamaria E, Ponce N, Zipa Y, Ferro C. Presence of infected vectors of Leishmania $(V$.$) panamensis within dwellings in two endemic$ foci in the foothill of the middle Magdalena valley, western Boyaca, Colombia. Biomedica. 2006; 26(Suppl. 1): 82-94.

Thomas A, Best N, Lunn D, Arnold R, Spiegelhal D. GeoBUGS user manual version 1.2 [Internet]. MRC Biostatistics Unit [cited 2012 Feb 9]. 2004. Available from: http://www.mrc-bsu.cam.ac.uk/ software/bugs/.

Thomson MC, Elnaiem DA, Ashford RW, Connor SJ. Towards a kalaazar risk map for Sudan: mapping the potential distribution of Phlebotomus orientalis using digital data of environmental variables. Trop Med Int Health. 1999; 4(2): 105-13.

Turton SM, Freiburger HJ. Edge and aspect effects on the microclimate of a small tropical forest remnant on the Atherton Tableland, northeastern Australia. In: Laurance WF, Bierregaard RO, editors. Tropical forest remnants: ecology, management, and conservation of fragmented communities. Chicago: University of Chicago Press; 1997. p. 45-54.
Valderrama-Ardila C, Alexander N, Ferro C, Cadena H, Marin D, Holford TR, et al. Environmental risk factors for the incidence of American cutaneous leishmaniasis in a sub-Andean zone of Colombia (Chaparral, Tolima). Am J Trop Med Hyg. 2010; 82(2): 243-50.

Weber CJ. Update on global climate change. Urol Nurs. 2010; 30(1): 81-4.

WHO - World Health Organization. Cutaneous leishmaniasis: why are you neglecting me? Geneva: WHO; 2007.

Young DG, Duncan MA. Guide to the identification and geographic distribution of Lutzomyia sandflies in Mexico, the West Indies, Central and South America (Diptera: Psychodidae). Mem Amer Ent Inst. 1994; 54: 881 pp.

Zeilhofer P, Kummer OP, dos Santos ES, Ribeiro ALM, Missawa NA. Spatial modelling of Lutzomyia (Nyssomyia) whitmani s.l. (Antunes \& Coutinho, 1939) (Diptera: Psychodidae: Phlebotominae) habitat suitability in the state of Mato Grosso, Brazil. Mem Inst Oswaldo Cruz. 2008; 103(7): 653-60. 


\section{SUPPLEMENTARY DATA}

Bioclimatic variables as on the Bioclim website (http://www.worldclim.org/bioclim)

$\mathrm{BIO1}=$ Annual Mean Temperature

$\mathrm{BIO} 2=$ Mean Diurnal Range [Mean of monthly (max temp - min temp)]

$\mathrm{BIO} 3=$ Isothermality $(\mathrm{BIO} 2 / \mathrm{BIO} 7)(* 100)$

$\mathrm{BIO} 4=$ Temperature Seasonality $($ standard deviation $* 100)$

BIO5 $=$ Max Temperature of Warmest Month

BIO6 $=$ Min Temperature of Coldest Month

$\mathrm{BIO} 7=$ Temperature Annual Range $(\mathrm{BIO5}-\mathrm{BIO})$

$\mathrm{BIO} 8=$ Mean Temperature of Wettest Quarter

BIO9 $=$ Mean Temperature of Driest Quarter

BIO10 $=$ Mean Temperature of Warmest Quarter

BIO11 $=$ Mean Temperature of Coldest Quarter

$\mathrm{BIO12}=$ Annual Precipitation

$\mathrm{BIO13}=$ Precipitation of Wettest Month

BIO14 $=$ Precipitation of Driest Month

BIO15 $=$ Precipitation Seasonality (Coefficient of Variation)

BIO16 $=$ Precipitation of Wettest Quarter

$\mathrm{BIO17}=$ Precipitation of Driest Quarter

BIO18 $=$ Precipitation of Warmest Quarter

BIO19 $=$ Precipitation of Coldest Quarter

Equation of the model (spatio-temporal statistical model) - Assuming that the occurrence of cases of cutaneous leishmaniasis $\left(Y_{i t}\right)$ in a municipality of $N_{i}$ inhabitants follows a Poisson mixture distribution with mean $\mu_{i t}\left(\mu_{i t}=Y_{i t} /\right.$ $\left.N_{i}\right)$, the random-effects Poisson model used is:

$Y_{i t} \sim$ Poisson $\left(\mu_{i t}\right) \quad i=1, \ldots, 715, t=1, \ldots, 9$

$\log \mu_{i t}=\log N_{i}+a_{0}+a_{t}+a_{i j} x_{i j}+b_{i}+h_{i} \quad j=1, \ldots, 31 \quad t=1, \ldots, 9$

Where:

$Y_{i t}$ is the number of cases of cutaneous leishmaniasis in the municipality $i$ and year $t$

$\mu$ is the incidence rate of cutaneous leishmaniasis in the municipality $i$ and year $t$

$N_{i}$ is the number of inhabitants in the municipality $i$

$a_{0}$ is the intercept

$a_{t}$ is the parameter capturing the time (year) from 2000 to 2009, with 2004 as the reference level

$x_{i}$ are the 31 independent variables (land use, temperature, rainfall, elevation and population density) with regression coefficient $a_{i j}$

$a_{i j}$ is the parameter capturing incidence effect in the municipality $i$ and independent variable $j$

$b_{i}^{i j}$ are spatial random effects with conditional autoregressive (CAR) structure (Thomas et al. 2004)

$h_{i}$ is the unstructured component of the random effect in the area $i$ 
普

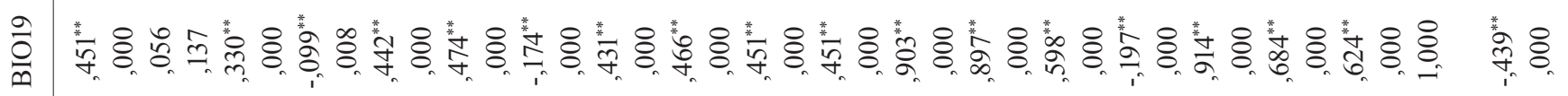

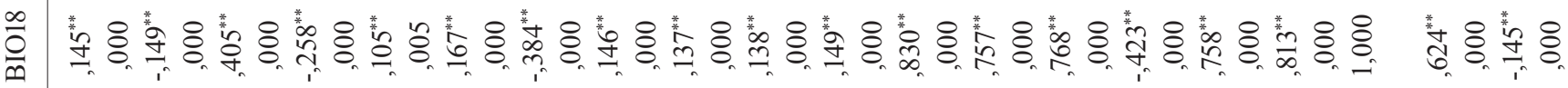
产 总 \&

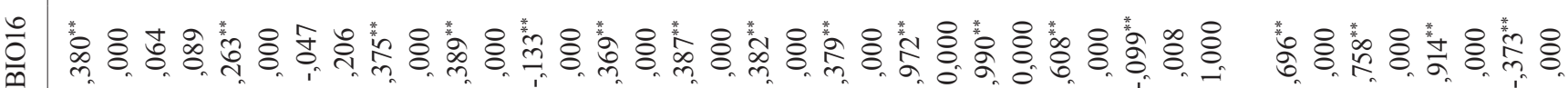

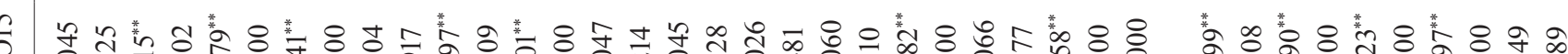
ळ

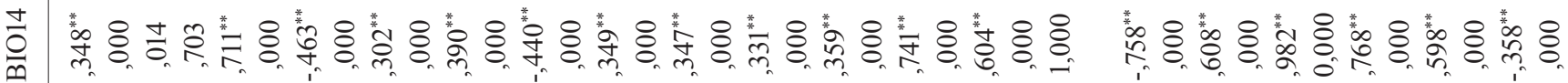

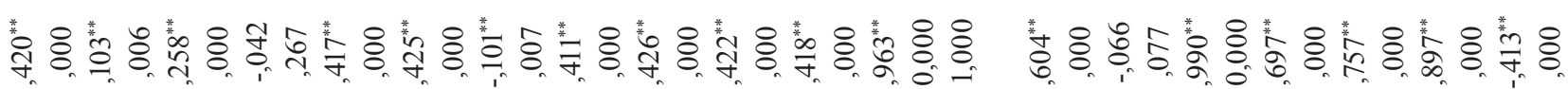

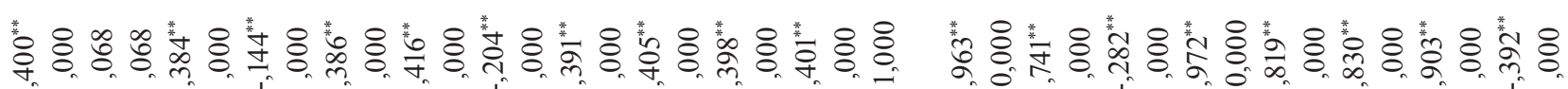

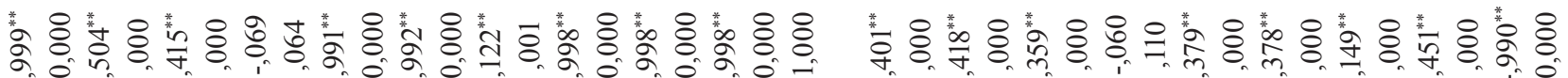
*

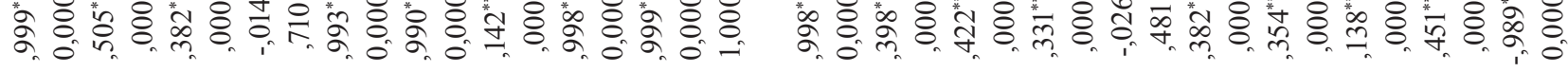

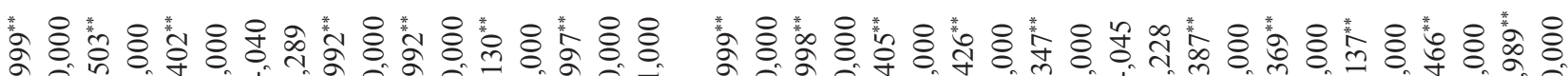

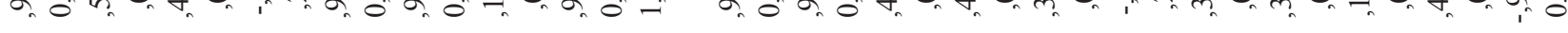

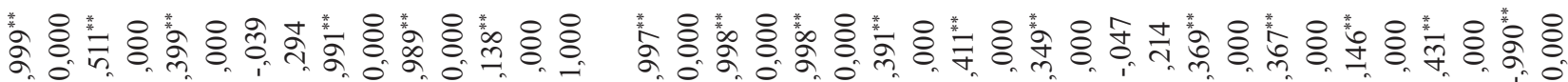

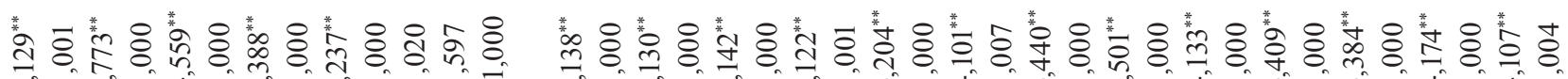
*O:

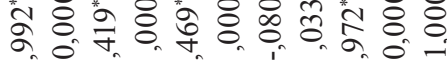

$\dddot{\vartheta}$

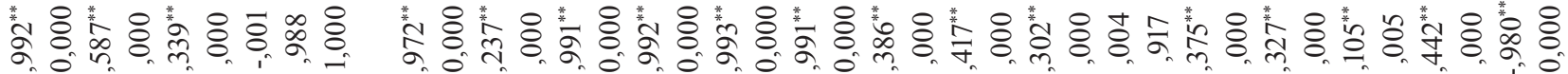

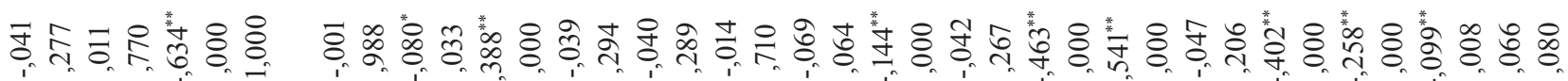

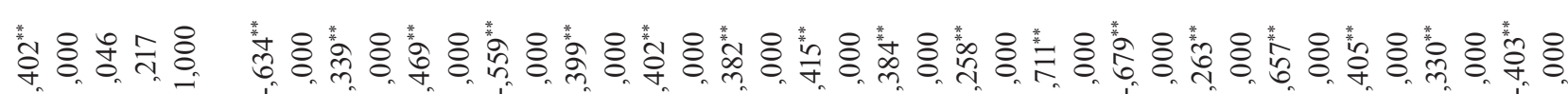

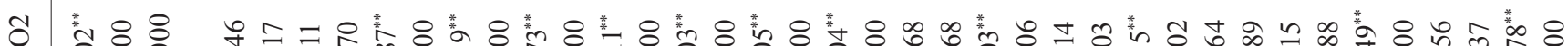

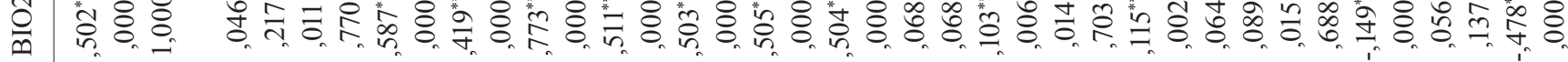
○ \&

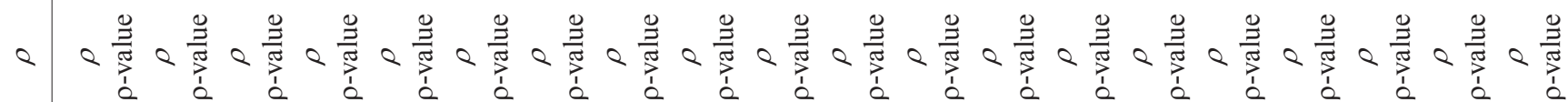
寧 
BIO1: Annual Mean Temperature

BIO2: Mean Diurnal Range [Mean of monthly (max temp - min temp)]

BIO3: Isothermality (BIO2/BIO7) $(* 100)$

BIO4: Temperature Seasonality (standard deviation *100)

BIO5: Max Temperature of Warmest Month

BIO6: Min Temperature of Coldest Month

BIO7: Temperature Annual Range (BIO5-BIO6)

BIO8: Mean Temperature of Wettest Quarter

BIO9: Mean Temperature of Driest Quarter

BIO10: Mean Temperature of Warmest Quarter

BIO11: Mean Temperature of Coldest Quarter

BIO12: Annual Precipitation

BIO13: Precipitation of Wettest Month

BIO14: Precipitation of Driest Month

BIO15: Precipitation Seasonality (Coefficient of Variation)

BIO16: Precipitation of Wettest Quarter

BIO17: Precipitation of Driest Quarter

BIO18: Precipitation of Warmest Quarter

BIO19: Precipitation of Coldest Quarter

Elev: Elevation

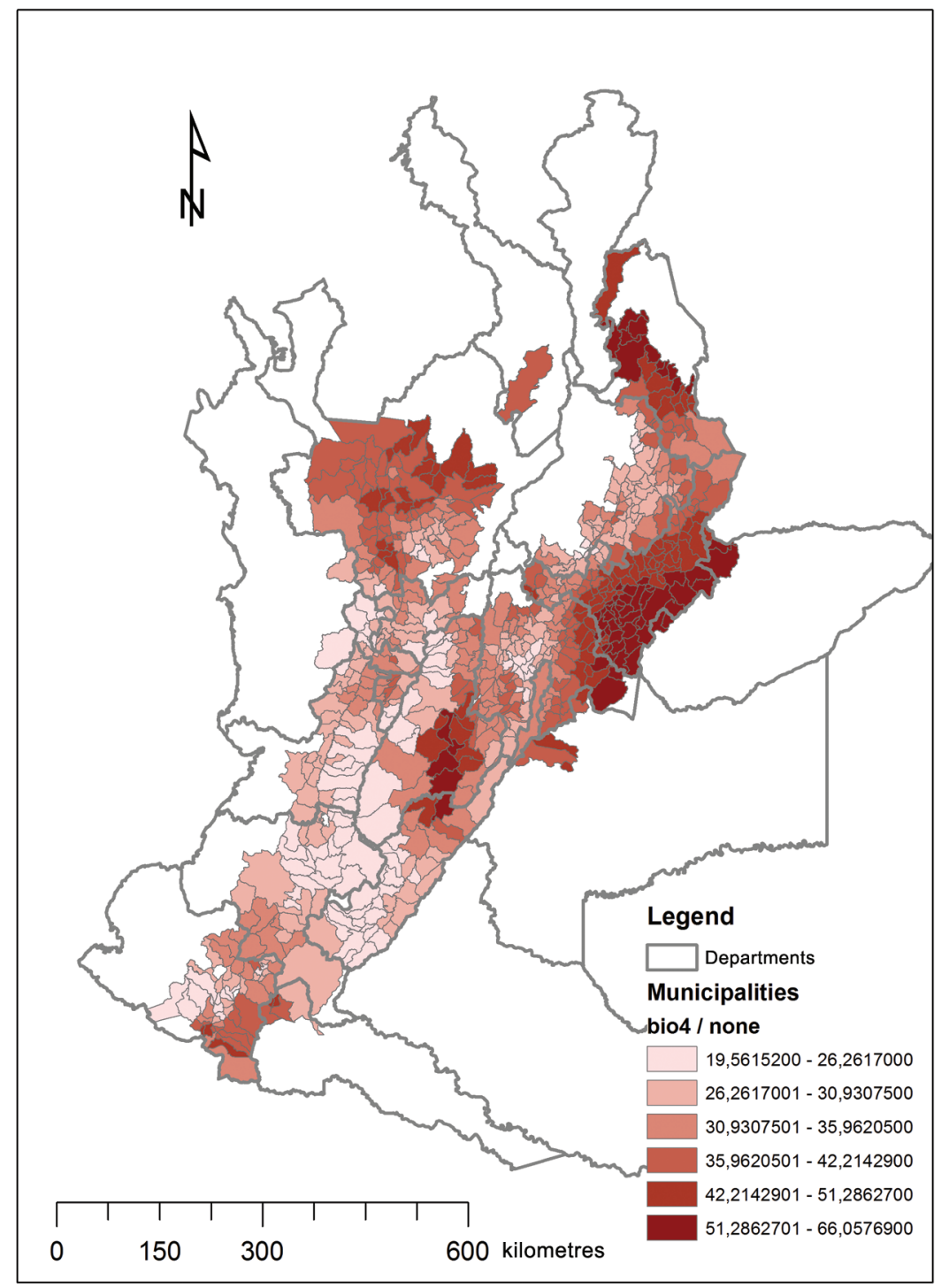

Map of temperature seasonality (standard deviation *100) - Bio4 - for Andean region of Colombia. 